\title{
TOGETHER THEY ARE STRONG: THE QUEST FOR SERVICE MODULARIZATION PARAMETERS
}

\author{
Research in Progress
}

Peters, Christoph, Kassel University, Kassel, Germany, christoph.peters@ uni-kassel.de

\begin{abstract}
This research-in-progress paper deals with service modularization of complex services. The successful creation of powerful modules allow leveraging modularization benefits such as reuse, faster development, module-wide innovation, and rapid reconfiguration. Consequently, service provider efficiencies as well as user centricity can be realized. Therefore, the principles of modularization, i.e. cohesion and loose coupling, need to reflect interdependencies between the "right" attributes. These attributes, e.g. know-how specificity or IT support, serve two functions. First, they are attributes of the underlying processes that make up the service which needs to be modularized. Second, they serve as candidates for modularization parameters. The paper's research setting comprises expert workshops and in which modularization parameters are applied. As a first result, I(1) suggest a set of mandatory modularization parameters that are derived from the literature and (2) call for domain-specific extensions. Thus, I contribute to service modularization research by providing the ingredients (modularization parameters) for the recipe (the overall method) for systematic service modularization of complex services. Thus, I also assist service providers in their modularization attempts which might be in need of "ingredients" as well and thereby make a contribution to practice.
\end{abstract}

Keywords: service modularization, complex services, modularization parameters.

Service has grown into an important field for research in information systems (Rai and Sambamurthy, 2006), as information technology (IT) is currently revolutionizing the way services are delivered. Many services hereby not only play a key role for societal advancements, but become necessary for it (Leimeister and Peters, 2012). On the one hand, IT enables new forms of cooperation and communication in service (Rai and Sambamurthy, 2006); on the other hand, it enables automation, standardization, and new concepts for customer integration (Fitzsimmons and Fitzsimmons, 2005). Regarding both, service modularization plays a key role.

There are first attempts to perform service modularization in a systematic manner (Peters and Leimeister, 2013). So far and to the best knowledge of the author, none of such attempts show or explain how modules are created out of a process repository. This is because the actual and quite operational act of modularization relies on the rigorous selection of modularization parameters and is complicated as well as time-consuming. Modularization parameters can be regarded as the set of criteria that processes are assessed on. Consequently, the modularization parameters predefine if and how processes are tied together in one module or not. Modules are formed by cohesion and loose coupling, i.e. the interplay between dependencies of processes. That is why parameters for 
modularization that are well selected, create powerful modules. The paper's title "Together they are strong" applies for the processes constituting such modules.

This paper has the ambition to make service modularization more explicit. It provides insights into the "black box" modularization which is often encountered. Thereby it makes a difference to other modularization projects that leave both, researchers and practitioners with a "magic happens here" when it comes to the core of modularization. When service modularization can be described as "the act of module creation" for non-modular services, then the research gap is the recipe to do so for complex services in a repeatable manner that is based on a certain set of criteria which are named modularization parameter in the remainder of this paper. That is why the aim of this paper is to shed light on the question: How can modularization be operationalized? My answer is: by using modularization parameters and thereby constituting the mechanism which brings service providers from non-modularized services to modularized ones that can leverage modularization potentials as described in section 2.1 .

The paper at hand is structured as follows: In the following section, foundations are laid by defining and describing core concepts of this paper: service modularization, modularization principles and complex services. Next, I outline modularization parameters that are derived from the existing body of knowledge and give an example why a set of these criteria is needed. In a detailed fashion, I describe the research setting. The research design incorporating expert workshops is outlined. First results and preliminary findings follow, before I conclude and summarize our main contributions and present future research's potentials.

\section{$2 \quad$ Background}

\subsection{Service Modularization}

While many authors have dealt with service modularization already (Bask, Lipponen, Rajahonka and Tinnilä, 2010; de Blok, Luijkx, Meijboom and Schols, 2010; Tuunanen and Cassab, 2011; Voss and Hsuan, 2009) and the concept and effects of service modularization have been elicited (Dörbecker and Böhmann, 2013), it can be seen that the systematic modularization in form of modularization methods is very rarely applied to the field of services. And existing methods (Böhmann, Langer and Schermann, 2008) are not adequate for dealing with complex services (Peters and Leimeister, 2013). Thus, I identified the research gap of systematic service modularization of complex services and we already elaborated an according method (Peters and Leimeister, 2013).

Common potentials of service modularization (Schermann, Böhmann, Prilla, Herrmann and Krcmar, 2012) are manifold: reuse - the repeated use of one specific module within different services; faster development - the increase of overall development speed through higher manageability due to smaller objects of consideration (the modules) that have defined interfaces; module-wide innovation - the possibility to concentrate innovation efforts within one strategically important module that is supposed to provide competitive advantages; rapid reconfiguration - the efficient (re-) configuration of modules enables a customer-centric service provision in a mass customization manner.

From a granularity perspective, modules can be considered an aggregation of one or more processes. In this paper, a service has the lowest granularity level while processes have the highest granularity level considered. Subsequently, modules are positioned between processes and services.

\subsection{Modularization Principles}

Modularization rests upon the basic principles of cohesion and loose coupling (Balzert, 1996). Cohesion describes the extent of intra-module dependencies. A high cohesion is a requirement for 
well-specified modules that can be reused and combined with other service modules. Loose coupling (Böhmann and Krcmar, 2006) means that there are only few inter-module dependencies between the elements of the different modules. So, loose coupling directs to the independence of the modules. Modules serve a specific function (Schilling, 2000) and "information hiding" takes place, i.e. moduleinternal attributes are hidden to the outside (Parnas, 1972).

Modules are connected by interfaces which have to be specified appropriately, too. In the context of complex services, this means that coming from a process-perspective, several processes can be combined to one module while they all together make up one service offering.

\subsection{Complex Services and Domain Specifics}

A service itself is "(a set of) activities being part of interactions between the components of service systems" (Leimeister, 2012). It is a complex phenomenon. Within the scope of this paper, complex services consist of a combination of both, IT and non-IT services, while the latter also integrate highly knowledge-intense, person-oriented (Menschner, Peters and Leimeister, 2011) and interactive parts as well.

Within the service sector, more and more complex services come into existence. As an example for such complex services, the field of telemedicine can be taken and is used for illustration purposes in the remainder of this paper. Complex services are further characterized by a large number of stakeholders (Georgi and Peters, 2013), e.g. in the field of telemedicine by physicians, care personnel, service providers, technology manufacturers or telecommunication companies. Telemedicine hereby is the provision of medical services over geographic distances through the use of information and communication technology (DGTelemed, 2011) and is outlined in 2.3.1 in more detail.

In this setting, modularization has the potential to foster service aggregation even across different stakeholders. Additionally, complex services are defined by a high degree of heterogeneity because of their person-oriented fashion. Modularization can offer the possibility to mass customize individual offerings, e.g. by allowing optimal treatment at reasonable cost (Peters and Menschner, 2012) in telemedicine where each patient's need is slightly different, a result of different life situations, state of disease, insurance coverage, etc.

\subsubsection{The field of telemedicine}

Telemedical services (TMS) comprise a very heterogeneous market (Leimeister and Peters, 2013), ranging from telemonitoring services (e.g., defibrillators that capture and transfer the patients' heart beat data in order to enable physicians to monitor the patients' heart functions remotely and to trigger alarm functions automatically) to teleconsultation services that enable experts to guide other physicians through the conduction of medical procedures, e.g., in telestroke units. TMS are therefore beneficial in supporting a patient's quality of life (Berry and Bendapudi, 2007) and, where implemented, can reduce the cost of delivering health care. Despite being considered medically and technically viable, few TMS innovations have been put into practice (Cho, Mathiassen and Gallivan, 2008; Essén, 2009). The reasons TMS are not seeing a widespread implementation include a lack of suitable business models, difficulties in integrating them into existing health care treatment processes, and usability and acceptance issues on the part of physicians and patients. The market for telemedicine is continuously growing, from $\$ 9.8$ billion in 2010 to $\$ 23$ billion in 2015 (BCC Research, 2011) worldwide and reaching $\$ 5$ billion in 2015 within the European market (European Commission, 2014). For service providers who want not only to benefit from this expected growth but also to leverage their own market potentials in a competitive market, this prospect calls for flexibility in this fast-changing market. 


\section{$3 \quad$ Modularization parameters}

Modularization efforts always need to be dependent on its costs and benefits. While modularization reduces the module-internal complexity, it also increases dependencies between processes which cause higher needs for communication and coordination as well as resource constraints and costs accordingly (Schantin, 2004). This trade-off needs to be taken into account. It is also reflected in the choice of the service provider for relevant and strategically critical modularization parameters. This is important as these parameters influence whether modules become basic / mandatory modules of a service offering guaranteeing the main functionalities, or whether the module is defined as optional add-on.

Existing modularization parameters in the literature could be identified (Peters and Menschner, 2012; Schantin, 2004) and are as follows: Geographical specificity, device-specificity, time-critical path dependencies, know-how specificity, IT-support / (semi-) automation, personal encounter / customer integration. They are discussed in more detail in the research design section (workshop 2) below.

As described above a module is characterized by a high cohesion, i.e. strong intra-module ties, and loose coupling, i.e. low inter-module dependencies. Taking the example of geographical specificity and assuming that it would be the sole modularization parameter, this would mean that processes that take place at the same location qualify to be included in the same module. Of course (as geographical specificity is only one of many parameters), other parameters have to be considered as well.

\section{$4 \quad$ Research Setting}

This research can be seen as one important part in a bigger project developing a modularization method that is displayed in Figure 1.

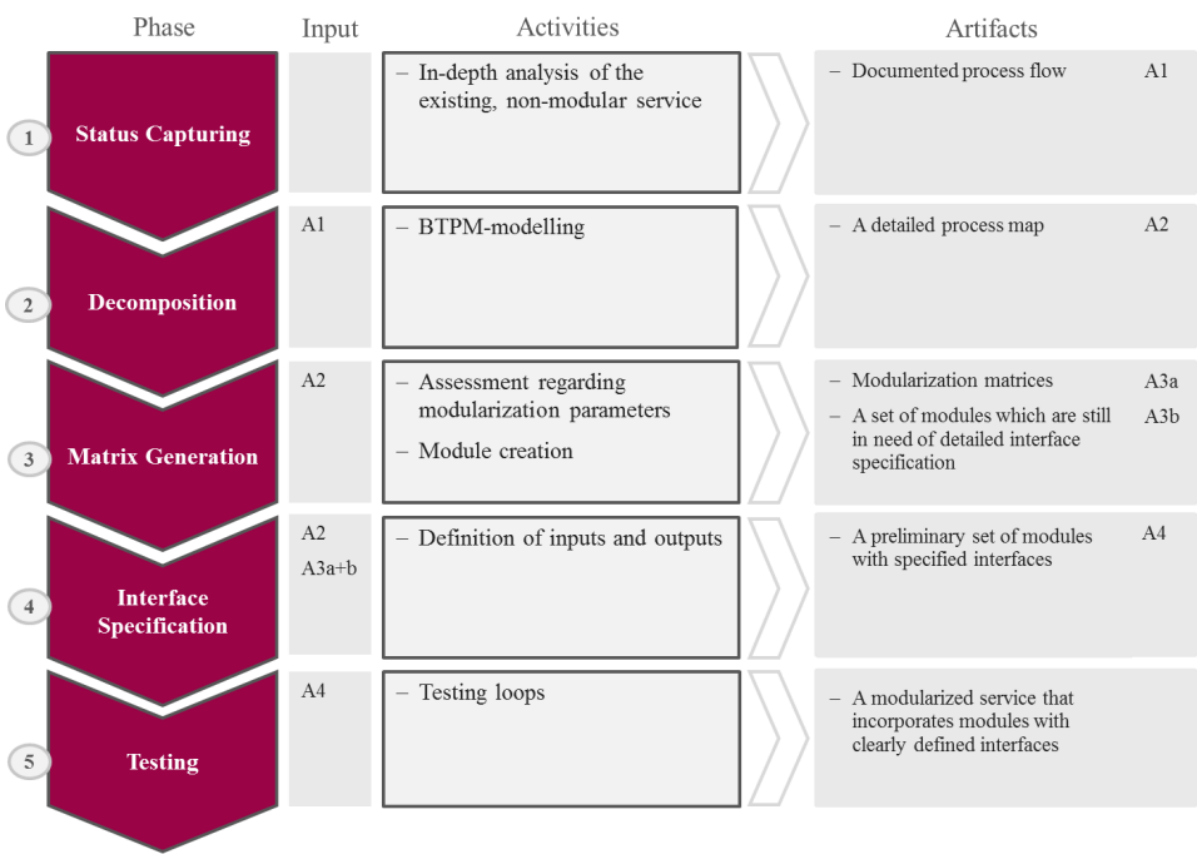

Figure 1: The modularization method and its phases; source: own illustration, (Peters and Leimeister, 2013). 
This project aims to develop a method that allows for the systematic modularization of services. In contrast to other successful modularization methods (Böhmann et al., 2008), it is adequate for complex services. The method itself consists of five phases, namely: (1) status capturing, (2) decomposition, (3) matrix generation, (4) interface specification, and (5) testing. Each of the phases incorporates according activities and resulting artefacts that are used as input for consecutive phases (Peters and Leimeister, 2013). The identification, selection and redevelopment or extension of relevant modularization parameters plays a key role of every modularization attempt and is located in Phase 3 (Matrix Generation) of the method.

\subsection{Research Design}

The conducted research is of qualitative nature and mainly incorporates expert workshops. The workshops are conducted at the site of a service provider in the field of telemedicine who serves as a partner in the overall project. An overview of the overall setting is illustrated in Figure 2.

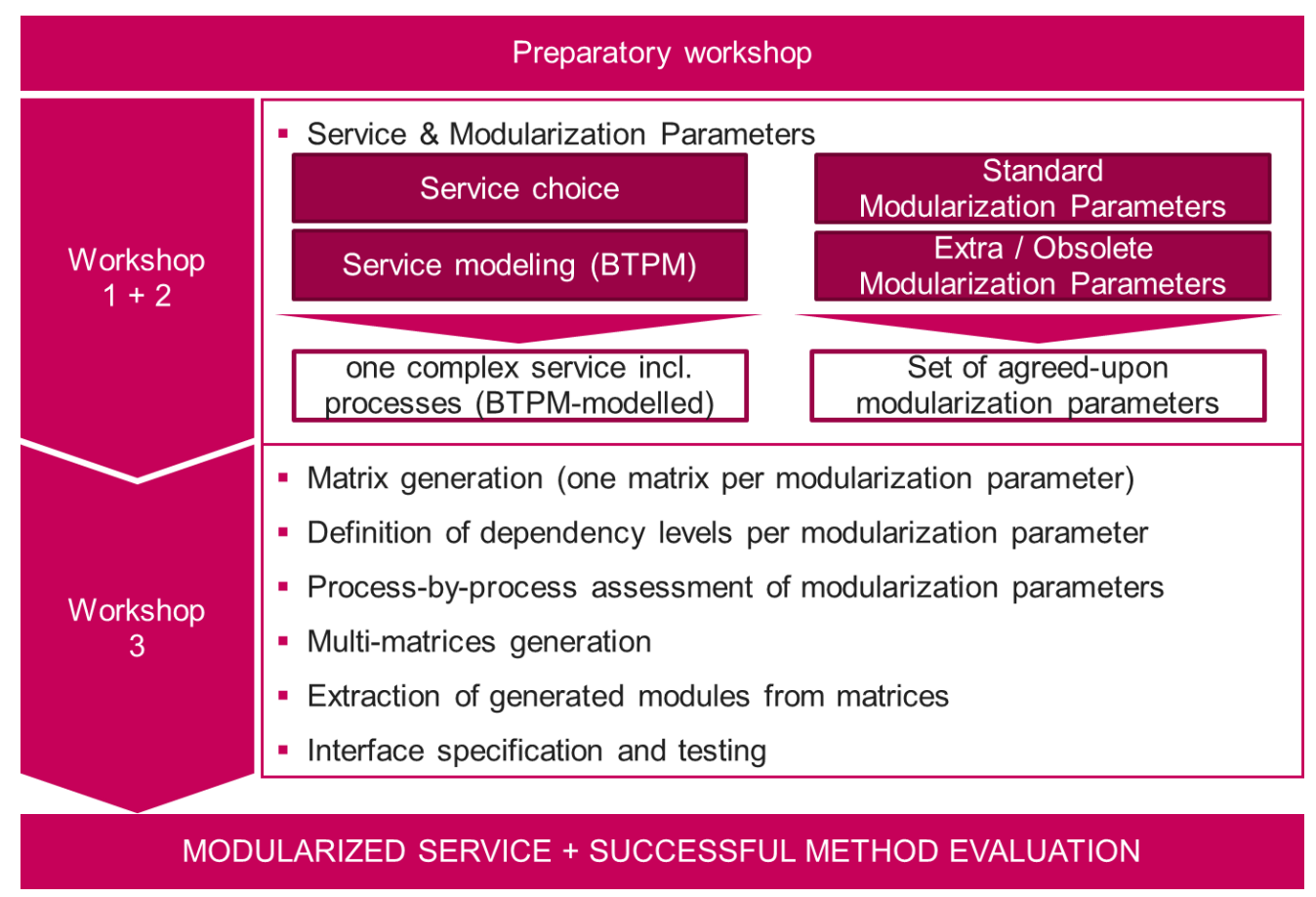

Figure 2: Overview of evaluation workshops

\subsubsection{The preparatory workshop}

Within this workshop, the fundamentals of modularization are outlined and an initial instantiation of the method and its application in the field is presented. The preparatory workshop was designed to last three hours. Its goal was to depict the benefits modularization of complex services is going to provide. It also served as the basis to decide on the to-be-modelled service. Also, the overall workshop setting in regards to content and timeframes was planned within the preparatory workshop. 


\subsubsection{Workshop 1: Service decomposition and modeling}

The workshop has two functions. First, it is a follow-up from the preparatory workshop. Second, it delivers outcomes that are prerequisites for the following workshops. It comprises:

Service identification and illustration: one dedicated service needs to be chosen that needs to fulfill the following criteria. It should be a frequently provisioned service. It should be not a trivial, but a complex service, i.e. - as defined above - it consists of IT as well as non-IT parts and comprises the integration of other stakeholders. Then, this service should be clearly described and illustrated.

Service Modelling: The chosen service is modelled with BTPM (Peters and Leimeister, 2014), the Blueprint-driven Telemedicine Process Modelling language, a specific modelling language for the field of telemedicine.

Modeling assists in the clear representation of services. This is of special need in service systems such as telemedicine which inherits complex services. That is why the decomposition in phase 2 of the modularization method explicitly addresses that by using BTPM. This language was further developed and evaluated (Peters and Leimeister, 2014). This is described in detail in the paper which presents how the workshop-informed, iterative design and two-fold evaluation (by application and by criteria) of BTPM was conducted in an action research (AR) setting.

The newly developed language inherits the well-known BPMN-concept of pools and lanes which allows for modular stakeholder-extensions. It integrates blueprinting-specific elements, e.g. the line of interaction or the line of visibility, in order to represent both, value-creating face-to-face momenta as well as front- and backstage activities. Also, BTPM explicitly considers telemedicine devices and distinguishes between stakeholder groups using color coding. It could be shown that BTPM not only meets requirements which have been elicited in case studies performed earlier (thus standing the criteria-based evaluation), but also all additional requirements that came up during the three iterations in the workshops. When applying it (evaluation by application), its adequacy to also assist with the separation of main and sub-processes of services and the identification of (semi) automation and customer integration potentials, could be shown.

AR's dual imperative, i.e. its problem-solving and research interest, corresponds to the paper's contribution which lies in the design and two-fold evaluation of the modeling language and in the interdisciplinary research setting for its development.

\subsubsection{Workshop 2: Modularization Parameters}

On the journey to beneficial modularization of complex services, the right choice of modularization parameters can be regarded critical as reasoned above.

That's why within this workshop, the final set of parameters for the modularization matrices is determined. Based on these, the process-by-process analyses are carried out in workshop 3 accordingly. The derivation of parameters evolved by:

- Reflection of already existing modularization parameters: The described modularization parameters that are known from the literature are studied and discussed. So far, the following parameters could be elicited:

- Geographical specificity: There are processes that require a certain surrounding and others taking place in different locations. Non-virtual processes that are closer (in a geographical sense) might be important to consider here. The pools and especially lanes of the process map provide indicators here. 
- Device-specificity: Some processes are coupled to a certain device. If so, modularization which is performed in awareness of device specificity tries to avoid frequent media breaks.

- Time-critical path dependencies: All processes within paths that run in parallel and are merged later on need to be checked whether they inherit critical time constraints which have crucial effects on the after-merge processes.

- Know-how specificity: There are processes which require a high knowledge and know-how which is closely related to the person's educational background performing it. An example for a process with high know-how specificity is a surgery.

- IT-support / (semi-) automation: Here, a check for potential IT-support and (semi-) automation is performed. This is important when it comes to cost reduction purposes. All parts which are not value-creating, but can be considered commodity highly qualify here.

- Personal encounter / customer integration: In complex services, many services integrate person-to-person parts; many of these personal encounters make up a high fraction of valuecreating moments. Stakeholders, especially customers, can be integrated in the service provision. According to (Glushko, 2009), there are different levels of integration; the highest one being a self-service setting.

- Extra / obsolete modularization parameter: Additional and obsolete parameters can be suggested and are then discussed and agreed upon. This might be necessary due to specifics inherent to the company and its strategic goals, the field and according regulations, etc.

After successful conduction of these steps, the third workshop can be conducted. In terms of the overall project and the according method, this is the point in which the matrix generation can start.

\subsubsection{Workshop 3: Modularization Matrices, Specification and Testing}

Workshop 3 builds on the steps outlined before. It is designed to last 4 hours. This determination is based on extensive workshop experience. All participants are provided with the service which is modelled in BTPM. Then, the dependency levels for each parameter are defined before all process steps are assessed in regards to the modularization parameters in a process-by-process manner. This is done for all modularization parameters that were agreed on before. For every modularization parameter one dedicated design structure matrix is created. A design structure matrix is "a straightforward and flexible modelling technique that can be used for designing, developing, and managing complex systems" (Eppinger and Browning, 2012). The several process steps of the service make up the matrix axes and the process dependencies are represented in the according fields of the matrix. As there will be more than one modularization parameter, consequently there will be more than one created matrix. In case particular modularization parameters are of higher importance than others, a weighting of the parameters is performed now (by multiplying the values of more important parameters with an according factor). It is also considered to combine all these matrices into one socalled multi-domain matrix (Maurer and Lindemann, 2008) as they are used in complexity management and systems engineering. Doing so would allow assessing the modularization parameters in a very structured manner. It would also provide module solutions that are derived based on calculation and thus, could be easily compared. So far, the multi-domain matrices could be assessed to be suitable, but a tool for proper use could not be identified. Still, the creation of this matrix is supposed to identify modules that should be created. The created modules are then analyzed in regards to their interfaces to other modules or service parts and after the newly created structure of the service is established, it is tested. It is planned to integrate elicited matrix-driven modularization approaches (Dörbecker and Böhmann, 2014) in this workshop. 


\section{$5 \quad$ Findings so far and Preliminary Conclusion}

The first workshop has been already conducted and is of preparatory nature. Four experts from the field of telemedicine were involved. Their roles are best described as: (1) founder and CEO, (2) chief developer, (3) process analyst and requirements engineer as well as (4) service process expert.

In the workshop, the understanding of modularization was sharpened and illustrated using an example service which has been successfully modularized in an earlier setting. It was agreed that one service from the provider will be modelled collaboratively in an online cloud environment that allows all modellers to adapt and comment existing service models. Therefore, BTPM will be used. Also, several service candidates were already discussed which might be most valuable to modularize. The final choice for the pilot service will be chosen soon; in regards to its potential for strategic competitive advantages. The existing modularization parameters were briefly introduced and discussed. This can be regarded successful as it became clear by the illustrated example service. I consider these existing parameters as the mandatory set every service modularization of complex services should include. The expectation is that there will be two or three extra modularization parameters. They are then used in the main workshop and emerge from the domain specifics, e.g. the law for medical products in Germany that asks for certification and data protection requirements.

An important finding that could be made already is that modularization parameters can and must be distinguished between the ones that can be assessed by a single process and the ones that need pairwise assessment. As an example for single process assessment, the know-how in a specific field for one process can be taken, while the time-critical path dependencies serve as an example for assessments in need for pair-wise assessments of processes.

As next steps, last preparations for the following workshops are undertaken. The aim and expectation of the workshops is that the one chosen service can be transformed from a completely nonmodularized fashion to a modular service. Thus, the potential benefits of service modularization are going to be leveraged.

\section{$6 \quad$ Expected Contribution and Future Research}

This paper outlines a suggestion how to operationalize modularization attempts using modularization parameters. Thus, it contributes to the research agenda for service systems engineering stating "novel work should seek to enhance the possibilities for modularization, standardization, contextualization and reconfiguration of service components and resources" (Böhmann, Leimeister and Möslein, 2014). In terms of practical contribution, it aims to allow service providers to realize modularization benefits by providing services in an efficient manner on the one side and in a customer-centric fashion on the other side and increases awareness for modularization needs and potentials.

In terms of future research it fosters further developments of modularization methods such as $\mathrm{TM}^{3}$ (Peters and Leimeister, 2013) and reveals insights for modularization approaches in related areas dealing with complex services as well. In this context, first attempts to systematically create culturerelated modules (Janson, Peters and Leimeister, 2014) is worth mentioning. The integration of the presented findings in settings that deal with whole service architectures and portfolios (Duennebeil, Sunyaev, Leimeister and Krcmar, 2013) seems promising as well.

\section{$7 \quad$ Acknowledgements}

The research presented in this paper is conducted within the project EDiMed, funded by the German Federal Ministry of Education and Research (FKZ: 01FL10041). 


\section{References}

Balzert, H. (1996). Lehrbuch der Software-Technik, Spektrum, Akadamischer Verlag, Heidelberg, Berlin, Oxford.

Bask, A., Lipponen, M., Rajahonka, M. and Tinnilä, M. (2010). The concept of modularity: diffusion from manufacturing to service production, Journal of Manufacturing Technology Management, 21 (3), p. 355-375.

BCC Research (2011). Research Report Telemedicine: Opportunities for Medical and Electronic Providers, http://www.bccresearch.com/report/HLC014D.html, (Retrieved at: 17.03.2011).

Berry, L. L. and Bendapudi, N. (2007). Health Care: A Fertile Field for Service Research, Journal of Service Research, 10 (2), p. 11.

Böhmann, T. and Krcmar, H. (2006). Modulare Servicearchitekturen, In: Service Engineering (Eds: Bullinger, H.-J. and Scheer, A.-W.), Springer, Berlin, Heidelberg, Germany, p. 377-401.

Böhmann, T., Langer, P. and Schermann, M. (2008). Systematische Überführung von kundenspezifischen IT-Lösungen in integrierte Produkt-Dienstleistungsbausteine mit der SCORE-Methode, Wirtschaftsinformatik, 50 (3), p. 196-207.

Böhmann, T., Leimeister, J. and Möslein, K. (2014). Service Systems Engineering, Business \& Information Systems Engineering, 1-7.

Cho, S., Mathiassen, L. and Gallivan, M. (2008). Crossing the Chasm: From Adoption to Diffusion of a Telehealth Innovation, In: Open IT-Based Innovation: Moving Towards Cooperative IT Transfer and Knowledge Diffusion Springer, Boston, p. 361-378.

de Blok, C., Luijkx, K., Meijboom, B. and Schols, J. (2010). Modular care and service packages for independently living elderly, International Journal of Operations \& Production Management, 30 (1), p. 75-97.

DGTelemed (2011). Telemedicine, http://www.dgtelemed.de/de/telemedizin/, (Retrieved at: 17.03.2011).

Dörbecker, R. and Böhmann, T. (2013). The Concept and Effects of Service Modularity - A Literature Review, In: Proceedings of 46th Hawaii International Conference on System Sciences (HICSS), Grand Wailea, Maui, Hawaii.

Dörbecker, R. and Böhmann, T. (2014). Modularisierung von Dienstleistungen - Methodische Unterstützung durch Matrix-basierte Ansätze In: Proceedings of Dienstleistungsmodellierung (DLM) 2014 Springer (to be published), Vienna, Austria.

Duennebeil, S., Sunyaev, A., Leimeister, J. M. and Krcmar, H. (2013). Modular Architecture of Value-Added Applications for German Healthcare Telematics, Business \& Information Systems Engineering (BISE), 5 (1), p. 3-16.

Eppinger, S. D. and Browning, T. R. (2012). Design structure matrix methods and applications, The MIT Press.

Essén, A. (2009). The emergence of technology-based service systems: A case study of a telehealth project in Sweden, Journal of Service Management, 20 (1), p. 98-121.

European Commission (2014). Telemedicine, http://ec.europa.eu/digital-agenda/en/telemedicine, (Retrieved at: 14.03.2014).

Fitzsimmons, J. A. and Fitzsimmons, M. J. (2005). Service management : operations, strategy, and information technology, McGraw-Hill/Irwin, Boston, p. xiv, 605 p.

Georgi, C. and Peters, C. (2013). Multidimensionale Vorteilhaftigkeitsbetrachtung von Dienstleistungen am Beispiel Telemedizin, CONTROLLING - Zeitschrift für erfolgsorientierte Unternehmenssteuerung, 25 (10), p. 528-535.

Glushko, R. J. (2009). Seven Contexts for Service System Design, In: Handbook of Service Science (Eds: Maglio, P. P., Kieliszewsk, C. A. and Spohrer, J.), Springer, New York. 
Janson, A., Peters, C. and Leimeister, J. M. (2014). Der Weg zur effizienten Bereitstellung kultursensitiver Dienstleistungen? Erste Schritte mittels systematischer Modularisierung, In: Proceedings of Dienstleistungsmodellierung (DLM) 2014 Springer, Vienna, Austria.

Leimeister, J. M. (2012). Dienstleistungsengineering und -management, Springer Verlag, Berlin and Heidelberg, Germany.

Leimeister, J. M. and Peters, C. (2012). Gesellschaftlich notwendige Dienstleistungen - soziale Innovationen denken lernen, WISO-Diskurs - Expertisen und Dokumentationen zur Wirtschafts- und Sozialpolitik(Ed: Arbeitspapier des Arbeitskreises Dienstleistungen der Friedrich-Ebert-Stiftung) Friedrich-Ebert-Stiftung, Abteilung Wirtschafts- und Sozialpolitik, Bonn, Germany.

Leimeister, J. M. and Peters, C. (2013). Telemedizin, In: Enzyklopädie der Wirtschaftsinformatik Online-Lexikon Vol. 7 (Ed: Kurbel, K. B., J.; Gronau, N.; Sinz, E. \& Suhl, L.), Oldenbourg, Munich, Germany.

Maurer, M. and Lindemann, U. (2008). The application of the Multiple-Domain Matrix: Considering multiple domains and dependency types in complex product design, In: Proceedings of Systems, Man and Cybernetics, 2008. SMC 2008. IEEE International Conference on IEEE,

Menschner, P., Peters, C. and Leimeister, J. M. (2011). Engineering Knowledge-Intense, PersonOriented Services - A State of the Art Analysis, In: Proceedings of Proceedings of the 19th European Conference on Information Systems (ECIS), Helsinki, Finnland.

Parnas, D. L. (1972). On the criteria to be used in decomposing systems into modules, Communications of the ACM, 15 (12), p. 1053-1058.

Peters, C. and Leimeister, J. M. (2013). TM³ - A Modularization Method for Telemedical Services: Design and Evaluation, In: Proceedings of Proceedings of the 21st European Conference on Information Systems (ECIS), Utrecht, the Netherlands.

Peters, C. and Leimeister, J. M. (2014). Modellierung telemedizinischer Dienstleistungen mit der Blueprint-driven Telemedicine Process Modeling Language, In: Produktivität von Dienstleistungen (Eds: Schultze, W. and Möller, K.), Springer (accepted / to be published), Germany.

Peters, C. and Menschner, P. (2012). Towards a Typology for Telemedical Services, In: Proceedings of Ancilliary Proceedings of the 20th European Conference on Information Systems (ECIS), Barcelona, Spain.

Rai, A. and Sambamurthy, V. (2006). Editorial notes - the growth of interest in services management: opportunities for information systems scholars, Information Systems Research, 17 (4), p. 327331.

Schantin, D. (2004). Makromodellierung von Geschäftsprozessen: Kundenorientierte Prozessgestaltung durch Segmentierung und Kaskadierung, Deutscher Universitäts-Verlag, Wiesbaden, Germany.

Schermann, M., Böhmann, T., Prilla, M., Herrmann, T. and Krcmar, H. (2012). Service Modularization for Customer-Specific Service Design Based on Highly Standardized Services, In: Implementing International Services (Eds: Böhmann, T., Burr, W., Herrmann, T. and Krcmar, H.), Gabler Verlag, Wiesbaden, p. 101-118.

Schilling, M. A. (2000). Toward a General Modular Systems Theory and its Application to Interfirm Product Modularity, Academy of Management Review, 25 (2), p. 312-334.

Tuunanen, T. and Cassab, H. (2011). Service Process Modularization, Journal of Service Research, 14 (3), p. 340-354.

Voss, C. A. and Hsuan, J. (2009). Service Architecture and Modularity*, Decision Sciences, 40 (3), p. 541-569. 